\title{
Recordando o verdadeiro dragão Entrevista com George Jackson
}

Tradução: Rafael Carduz Rocha

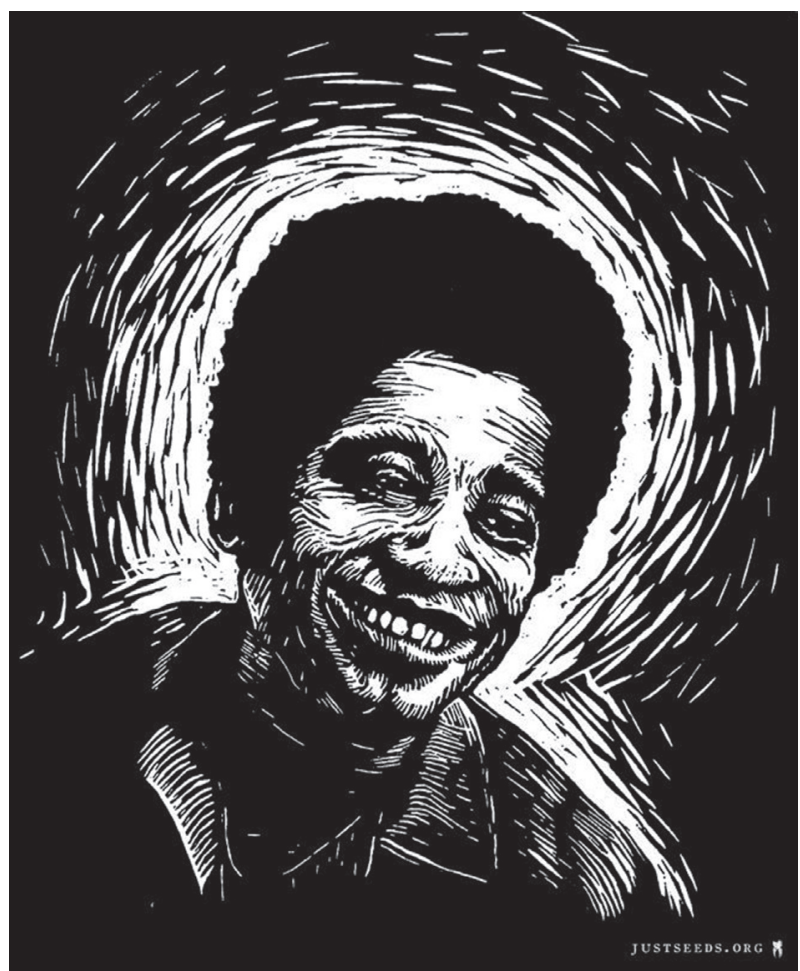

Xilografura de G. Jackson

Entrevista com George Jackson realizada por Karen Wald entre 16 de maio e 29 de junho de 1971.

Karen Wald é escritora, ativista e educadora com largo conhecimento sobre a educação em Cuba.

George Lester Jackson (1941-1971) foi membro do Partido dos Panteras Negras, participou das lutas sociais da década de 1960 nos Estados Unidos, preso por doze anos, foi assassinado em uma emboscada na prisão de San Quentin. O irmão de George, Jonathan, participou de uma tentativa de resgate de prisioneiros em Marin County, Califórnia em 1970. O caso ganhou repercussão nacional, entre outras razões, pela tentativa do governo estadunidense de envolver Angela Davis no caso. A prisão da ativista mobilizou campanha internacional, que termina vitoriosa com sua libertação. Jackson inspirou o cantor e compositor Bob Dylan, autor de uma canção em sua homenagem gravada em 1971. Os recentes acontecimentos em Nova Iorque fazer ver que continua vivo o contexto de repressão e abuso policial aos pobres e afrodescendentes nos EUA que deram origem aos Panteras Negras. 
A entrevista foi publicada em 1991, na obra Cages of Steel: The Politics of Imprisonment in America (Jaulas de aço: A Política de encarceramento nos Estados Unidos) de Ward Churchill. A versão em inglês se encontra disponível em http:// historyisaweapon.com/defcon1/jacksoninterview.html.

Karen Wald: George, você poderia falar sobre a sua concepção de revolução?

George Jackson: $O$ princípio da contradição entre opressor e oprimido pode ser reduzido ao fato de que a única maneira do opressor manter a sua posição é fomentando, alimentando, promovendo o desprezo ao oprimido. De que, depois de um tempo, as coisas saem do controle. Isso leva a excessos que podemos observar e os excessos são crescentes aqui no interior do estado totalitário. Os excessos produzem resistência; a resistência está crescendo. A coisa cresce em uma espiral. Ela só pode terminar de uma maneira. Os excessos levam à resistência, a resistência leva à brutalidade, a brutalidade leva a mais resistência, e, finalmente, a questão será resolvida com a custosa destruição dos oprimidos, ou com o fim da opressão. Estas são as tarefas da revolução. Ela cresce em espirais, confrontos, quer dizer, em todos os níveis. As instituições da sociedade reforçaram o establishment por isso eu digo que todos os níveis têm que ser atacados.

\section{Wald: Como o movimento de libertação da prisão se encaixa nisso? Sua impor- tância é exagerada ou artificial?}

Jackson: Nós não temos que exagerar nada... Veja, a tarefa particular na qual estou envolvido neste momento, o movimento da prisão foi iniciado por Huey P. Newton e pelo Partido dos Panteras Negras. Huey e o restante dos companheiros de todo o país. Estamos trabalhando com Ericka [Huggins] e Bobby [Seale, presidente do Partido dos Panteras Negras; naquele momento eles eram corréus em um julgamento por um assassinato em New Haven, Connecticut, após acusações que foram posteriormente derrubadas], o movimento dentro da prisão em geral, o movimento para provar ao establishment que a técnica de campo de concentração não funcionará conosco. Não temos que fantasiar qualquer importância para o nosso movimento em particular. É uma questão muito real, muito, muito real e eu sou da opinião de que, junto com o movimento estudantil, junto com o antigo Movimento dos Trabalhadores e das Famílias, o movimento de dentro da prisão é fundamental para o processo da revolução como um todo.

Wald: Muitos dos quadros das forças revolucionárias do lado de fora foram capturados e presos. Você está dizendo que mesmo que eles estejam na prisão, esses quadros ainda pode trabalhar de uma forma significativa pela revolução?

Jackson: Bem, estamos todos familiarizados com a função da prisão como uma instituição que serve às necessidades do estado totalitário. Nós temos que destruir essa função; ao final esta função não poderá mais ser viável. É uma das instituições mais fortes que apoiam o Estado totalitário. Temos que destruir a sua eficácia, e, é isso que representa o movimento de dentro da prisão. $\mathrm{O}$ que estou dizendo é que eles nos colocaram nestes campos de concentração, da mesma forma com a qual eles colocam as pessoas em jaulas de tigres ou "aldeias estratégicas" no Vietnã. A ideia é isolar, eliminar, liquidar as seções dinâmicas do movimento geral, os protagonistas do movimento. $\mathrm{O}$ que temos que fazer é provar que isso não vai funcionar. Temos que 
organizar a nossa resistência, uma vez que estamos dentro, não lhes daremos paz, a prisão vira apenas mais uma frente de luta, derrubá-la a partir de dentro. Compreende?

\section{Wald: Mas esta batalha pode ser ganha?}

Jackson: Uma boa parte disso tem a ver com a nossa capacidade de nos comunicarmos com as pessoas que estão na rua. A natureza da função da prisão no Estado policialesco tem que ser explicada de forma contínua, elucidada para as pessoas que estão na rua, porque nós não podemos lutar sozinhos aqui. Ah sim, podemos lutar, mas se estivermos isolados, se o Estado for bem sucedido na realização deste objetivo, os resultados não serão construtivos para provarmos nosso ponto. Lutamos e morremos, mas esse não é o ponto, embora possa ser admirável de um ponto de vista puramente moral. O ponto é, no entanto, diante do que enfrentamos, combater e vencer. Esse é o objetivo real: não apenas para fazermos declarações, não importa quão nobres sejam, mas para destruir o sistema que nos oprime. Através de todos os meios disponíveis para nós. E para fazer isso, temos que estar ligados, em contato e nos comunicando com aqueles que estão na luta do lado de fora. Devemos nos apoiar mutuamente porque estamos todos juntos nessa. Fundamentalmente é uma única luta.

\section{Wald: A forma de luta da qual você está falando aqui é diferente daquelas com as quais estamos mais familiarizados, como as que vêm ocorrendo no terceiro mundo, por exemplo?}

Jackson: Na verdade não. É claro que todas as lutas são diferentes, dependendo de toda uma variedade de fatores particulares envolvidos. Mas muitas dessas têm semelhanças fundamentais que são mais importantes do que as diferenças. Estamos falando de uma guerra de guerrilha no país. A guerrilha, o novo tipo de lutador que se desenvolve a partir de conflitos nos países do terceiro mundo, não luta necessariamente por glória. A guerrilha luta para vencer. A guerrilha luta o mesmo tipo de luta que lutamos, que é, às vezes, chamada de "guerra dos pobres.” Não é uma forma de guerra travada com armas de alta tecnologia, ou equipamentos de ponta. Eles lutam com as armas que podem ser capturadas, quando puderem ser, armas de fogo, muitas vezes antiquadas, bombas caseiras, facas, arcos e flechas, e até estilingues, mas principalmente através da força de vontade da guerrilha para lutar e vencer, não importa o que ocorrer. Huey [P. Newton] diz que "o poder do povo vai superar o poder da tecnologia do homem”, e já vimos essa verdade ser comprovado várias vezes na história recente.

Você sabe, guerra de guerrilha não é simplesmente uma questão de tática e técnica. Não são apenas questões de atacar e se esconder ou de terrorismo. É uma questão de provar à ordem estabelecida que ela simplesmente não pode se sustentar, que não há nenhuma maneira possível deles vencerem, utilizando os meios de força à sua disposição. Temos que provar que as guerras são vencidas por seres humanos, e não por dispositivos mecânicos. Temos de mostrar que no final eles não podem resistir a nós. E iremos! Nós o faremos. Não haverá um único momento de paz para qualquer um ligado ao establishment em qualquer lugar onde eu esteja, ou em qualquer lugar onde estejam meus companheiros. Mas nós vamos precisar de coordenação, nós vamos precisar de ajuda. E agora, a ajuda deve vir na forma de educação. É fundamental para ensinar as pessoas lá fora, como é importante para destruir a função da prisão dentro da sociedade. Isso, e mostrar-lhes em termos concretos que a guerra 
está sendo travada - agora mesmo! - e que, nesse sentido, nós realmente não somos diferentes dos vietnamitas, ou dos cubanos ou dos argelinos, ou de qualquer um dos outros povos revolucionários do mundo.

Wald: Em uma entrevista que fiz com alguns presos Tupamaros, da guerrilha urbana do Uruguai, foi levantada a questão sobre a dizimação das fileiras dos Tupamaros; camaradas mortos ou presos pelo Estado. Os entrevistados asseguram-me que havia muito mais pessoas que se juntam às fileiras do que as que são perdidas para a repressão do Estado, e que o movimento continua a crescer. Você tem a mesma confiança sobre o Partido dos Panteras Negras, sobre o movimento revolucionário como um todo neste país?

Jackson: Nós estamos estruturados de uma forma que nos permite existir e continuar a resistir, apesar das perdas que absorvemos. Foi preparado dessa forma. Sabemos que o inimigo opera sob o conceito de "matar a cabeça e o corpo vai morrer." Eles têm como alvo aqueles que eles enxergam como os principais líderes. Sabemos disso, e nós tomamos medidas para impedir que essa estratégia funcione contra nós. Eu sei que eu poderia ser morto amanhã, mas a luta vai continuar, haverá duzentas ou trezentas pessoas para ocupar meu lugar. Como Fred Hampton disse, "Você pode matar o revolucionário, mas você não pode matar a revolução.” Hampton, como você sabe, era chefe do partido em Chicago, e foi assassinado enquanto dormia pela polícia de Chicago, juntamente com Mark Clark, o líder do partido de Peoria, Illinois. Sua perda é enorme, mas a luta continua. Certo?

Não é apenas uma questão militar. É também uma questão educativa. As duas andam de mãos dadas. E também é uma coisa cíclica. Agora, estamos em um ciclo de pico. Há uma tremenda energia lá fora, dirigida contra o Estado. Não está toda focada, mas está lá, e se acumulando. Talvez isso seja suficiente para realizarmos e tudo o que temos que realizar a curto prazo. Vamos ver, e certamente esperamos que este seja o caso. Mas talvez não. Devemos estar preparados para travar uma longa luta. Se este for o caso, então nós provavelmente veremos um ciclo diferente, no qual a energia revolucionária do povo parecerá ter se dispersado, perderá pressão. Mas - e isso é importante - tais ciclos são enganosos. As coisas parecem estar na maré baixa, mas na verdade o que está acontecendo é um período de reagrupamento, um período em que damos um passo para trás e aprendemos com os erros cometidos durante o ciclo anterior. Nos educamos a partir de nossa experiência, e educamos aqueles que nos rodeiam. E o tempo todo, nós desenvolvemos e aperfeiçoamos o núcleo da nossa organização. Então da próxima vez que entrarmos em um ciclo de pico, estaremos muito mais prontos do que da vez anterior. É uma combinação do fator militar e do fator educativo, sempre. No final venceremos. Compreende?

\section{Wald: Você vê sinais de progresso no interior, na prisão?}

Jackson: Sim, eu vejo. O progresso certamente foi feito em termos de elevarmos a consciência de, pelo menos, alguns setores da população carcerária. Em parte, isso se deve às vitórias limitadas que alcançamos ao longo dos últimos anos. São talvez vitórias simbólicas, mas que podemos e devemos aproveitar. Por exemplo, temos lutado duro em torno da ideia de sermos capazes de nos comunicarmos diretamente com as pessoas do lado de fora. Neste ponto, qualquer pessoa na rua pode trocar cartas com qualquer indivíduo dentro da prisão. Minha sugestão é, agora que temos os canais 
para a educação garantidos, pelo menos temporariamente, as pessoas do lado de fora devem começar a bombardear as prisões com jornais, livros, revistas, recortes, qualquer coisa de valor educativo, para ajudar a politizar os companheiros que ainda não atingiram uma compreensão. E nós, é claro, devemos retribuir, de forma consistente através do envio de informações sobre o que está realmente acontecendo aqui. Aliás, as entrevistas como estas percorrerem um longo caminho nessa direção. Devem haver outras iniciativas como essa.

Wald: Você revelou a meses que é, já há algum tempo, membro do Partido dos Panteras Negras. Certamente, o trabalho do Partido no estado e em outros locais, o trabalho de libertar presos políticos e, claro, o trabalho do partido dentro da comunidade negra foram fatores que influenciaram essa sua decisão. Mas o internacionalismo do Partido foi um dos aspectos-chave que o atraiu para ele? $\mathrm{E}$, se este for $o$ caso, o internacionalismo tem algum significado para as pessoas presas, e é, portanto, uma razão pela qual essas pessoas se relacionam com o Partido?

Jackson: Bem, vamos dar um passo de cada vez. Huey veio à prisão há cerca de um ano atrás, porque ele havia ouvido falar das pequenas ações que já estávamos realizando. Ele conversou conosco, e nos checou, e então decidiu nos absorver. Depois, ele me enviou uma mensagem. Ele me disse que eu era parte do Partido agora, e que o nosso pequeno grupo fazia parte do Partido também. E ele me disse que o meu trabalho atual é construir, ou ajudar a construir, o movimento dentro da prisão. Apenas isso. Como eu disse, o objetivo do nosso movimento é provar que o Estado não pode nos isolar em um campo de concentração, então eu aceitei. O que mais eu poderia fazer? Foi a coisa certa. Agora, quanto ao seu segundo ponto, as pessoas dentro da prisão, à classe dos condenados, assumiu a ideologia do partido 100\%. E nós transitamos de ... Bem, não nós, eu sempre fui um internacionalista. E um materialista. Acho que eu era um materialista antes de eu nascer. Estou atualmente estudando Swahili para que eu possa ser capaz de conversar com os companheiros na África em seus próprios termos, sem ter que depender de uma língua colonial. E eu tenho estudado espanhol, que é, naturalmente, uma língua colonial, mas que é falada por milhões e milhões de camaradas na América Latina e em outros locais. Eu pretendo estudar chinês depois disso, e possivelmente árabe. Quando eu concluir esta tarefa, eu serei capaz de falar para cerca de setenta e cinco por cento das pessoas do mundo em sua própria língua, ou algo próximo a sua própria língua. Eu acho que isso é importante.

Os outros irmãos aqui estão também progredindo. E há alguns, especialmente aqueles que já eram politizados antes de virem aqui para dentro, que estão na frente. Mas como eu disse, é de extrema importância que as pessoas de fora bombardeiem este lugar com o material que irá ajudar os presos a compreender a importância do internacionalismo em sua luta. Estão chegando, mas ainda tem um caminho a ser percorrido antes que o processo educacional seja completado. A ignorância é uma coisa terrível, ser cortado do fluxo do movimento é realmente danoso. Temos que corrigir essa situação, como primeira prioridade.

\section{Wald: Você pode receber cartas e publicações de outros países?}

Jackson: Podemos receber cartas de qualquer lugar do planeta. Recebo agora coisas da Alemanha, da Inglaterra e da França, como resultado do livro ter sido publicado nesses países. E algumas cópias da Tricontinental começaram a chegar. Elas 


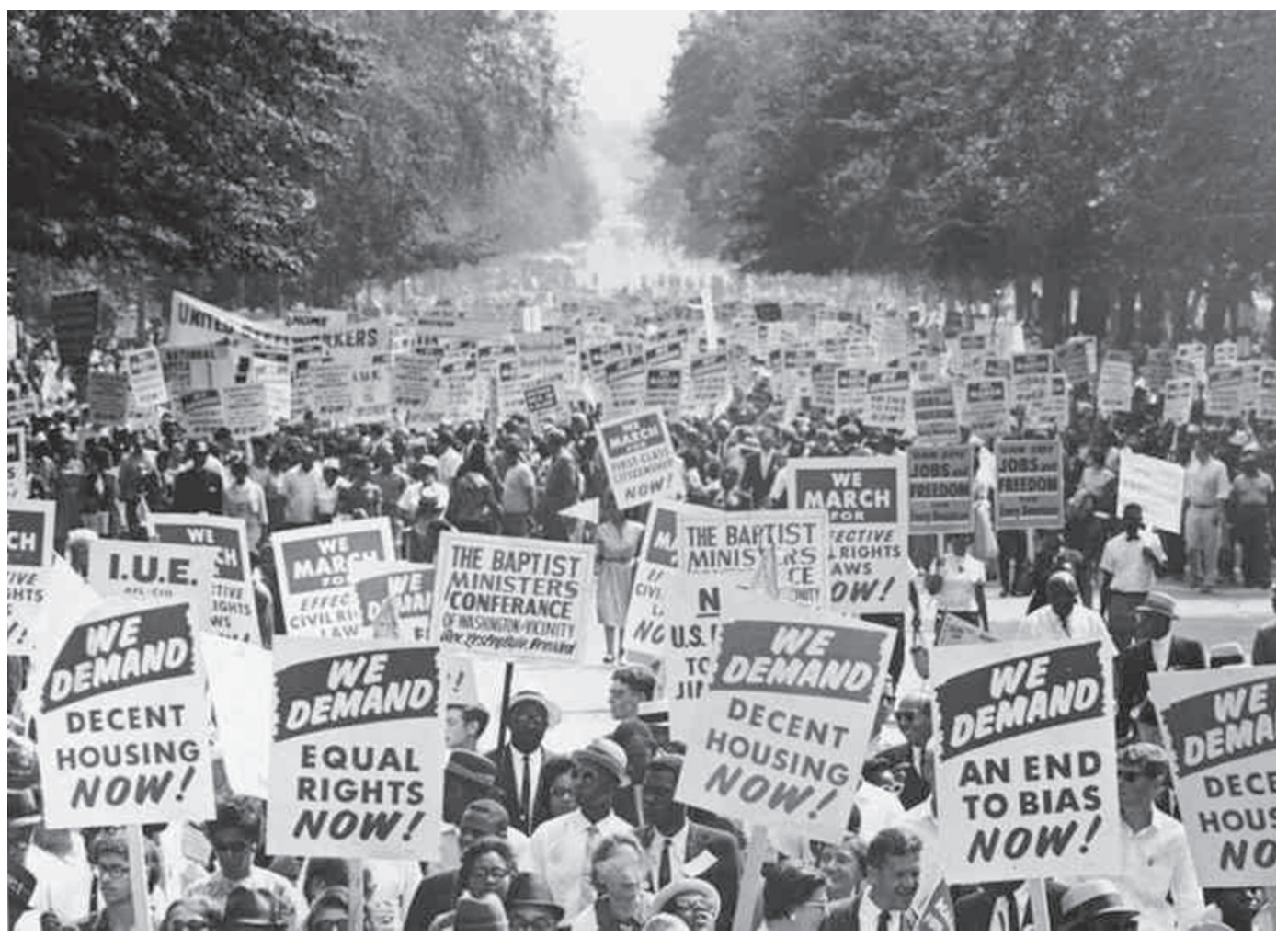

Marcha sobre Washington, 1963.

já ajudaram a ampliar a visão, e explicar aos companheiros algumas coisas que eles não entendem. Isso é algo que realmente perturba os tiras. Nos últimos anos, cada vez que um prisioneiro negro avançasse intelectualmente e começasse a relacionar a nossa situação com a situação dos cubanos, por exemplo, ou dos vietnamitas ou dos chineses, ou em qualquer outro lugar no Terceiro Mundo, bem esses prisioneiros seriam rapidamente assassinados. Agora se tornou um pouco mais difícil para eles fazerem isso. Então, eu acredito que as pessoas que estão na rua devem começar a inundar as prisões com coisas como a Tricontinental.

Wald: Apesar de algumas vitórias tranquilas na América Latina, como a de Salvador Allende no Chile, muitas pessoas ainda acreditam que a luta armada é o único caminho através do qual a maioria dos países latino-americanos se libertará. Além disso, houve algumas vitórias recentes nos tribunais para os membros do Partido dos Panteras Negras, o caso dos Siete de la Raza [sete ativistas latinos de São Francisco absolvidos da acusação de assassinato, em 1969], e assim por diante. Você acredita que as vitórias no Chile e nos tribunais...

Jackson: Foram apaziguamentos. Allende... A única coisa que aconteceu com Allende... Olha, não foi uma "revolução pacífica”. Isso é um erro. Allende é um bom homem, mas o que está acontecendo no Chile é apenas um reflexo das aspirações nacionais da classe dominante. Você nunca vai encontrar uma revolução pacífica. Ninguém entrega seu poder sem resistência. E até que a classe dominante no Chile seja esmagada, Allende pode a qualquer momento ser derrotado. Nenhuma revolução pode ser consolidada nas condições que prevalecem no Chile. $\mathrm{O}$ sangue correrá por lá. Ou Allende vai derramá-lo ao liquidar a classe dominante, ou a classe dominante 
vai derramar seu sangue, na hora que julgar certa. De qualquer forma, não há revolução pacífica. ${ }^{1}$

$\mathrm{O}$ mesmo pode ser dito para os processos judiciais aos quais você se refere. Eles são uma ilusão. De vez em quando o establishment relaxa em um caso, geralmente um que, para começar, era tão ultrajante que não poderia vencê-lo sem expor de alguma forma todo o seu sistema de injustiça, e então eles desatam a tagarelar sobre "a prova de que o sistema funciona", como ele é justo e correto. Eles nunca mencionam o fato de que as pessoas que deveriam ter recebido a justiça do sistema, muitas vezes passaram meses e meses encarceradas, e foram forçados a gastar milhares de milhares de dólares, buscando evitar passar anos e anos na prisão, antes de serem declaradas inocentes. Tudo isso para se defender contra acusações que não tinham nem base para serem apresentadas, e o estado sabia que não havia nenhuma base nelas. Em certos sistemas você começa a sua punição antes de seu julgamento, neste país se você for preto ou mulato ou político. Mas eles usam essas coisas para dizer que o sistema funciona, o que eu acho verdadeiro a partir da perspectiva deles, e para construir credibilidade para os casos que realmente contam, quando eles realmente querem despejar alguém em uma cela de prisão. A solução não é aprender a jogar com o sistema para ocasionais "vitórias" deste tipo, embora eu concorde que nestes casos, às vezes, representam uma vantagem tática. A vitória virá apenas com a destruição do próprio sistema. Nós nunca podemos nos enganar neste ponto.

Wald: Mas as alternativas, algumas vezes, têm consequências terríveis. Isso levanta a difícil questão da morte de seu irmão, Jonathan, e se sua vida pode, até certo ponto ter sido desperdiçada.

Jackson: Bem, isso é, obviamente, uma pergunta difícil para mim, porque, emocionalmente, eu gostaria muito de que meu irmão estivesse vivo e bem. Mas, se eu penso que a vida de Jonathan pode ter sido desperdiçada? Não, não creio. Acho que o único erro que ele fez foi pensar que todos os 200 porcos que estavam lá teriam algum tipo de preocupação com a vida do juiz. É claro que eles escolheram matar o juiz, e assumir o risco de matar o promotor distrital e os jurados, a fim de chegarem a Jonathan e aos outros. Pode ter sido um erro técnico. Mas eu duvido, porque eu sei que Jonathan estava muito familiarizado com as ideias militares, e eu tenho certeza de que ocorreu a ele que havia uma possibilidade de que pelo menos um porco fosse atirar, e que, se um atira, todos atiram, e que seria um massacre. Com juiz ou sem juiz. Era tudo um blefe gigantesco, sabe? Jonathan assumiu um risco calculado. Algumas pessoas dizem que isso faz dele um tolo. Eu digo que esse tipo de coragem é o que faz com que homens de sua idade sejam, em outras circunstâncias, agraciados com a Medalha de Honra do Congresso. A diferença é que Jonathan entendia de forma muito clara quem era o seu verdadeiro inimigo; enquanto que quem recebe a medalha do Congresso normalmente não. Agora, quem é o tolo?

1 Nota da edição em inglês: De acordo com a predição de Jackson, os militares chilenos - em conjunto com a CIA, Departamento de Estado de Kissinger, e com as corporações transnacionais (nomeadamente ITT e Anaconda) - derrubaram o governo Allende, em setembro de 1973. Mais de 30.000 progressistas e Allende foram mortos durante o golpe e nos três anos seguintes. Muitos outros milhares foram levados para o exílio permanente. Os chilenos foram confrontados com o regime neofascista do coronel Augusto Pinochet desde então. Embora as eleições "para inglês ver" ocorressem em 1989, Pinochet continua no comando dos militares. 
Pessoalmente, eu sinto muito essa perda. É um grande fardo sobre a minha alma. Mas eu acho que é imperativo - devemos isso a ele - nunca esquecer por que ele fez o que fez. Era para permanecer como um símbolo na frente das pessoas - na minha frente - e dizer de fato que temos tanto a capacidade quanto a obrigação de ficarmos em pé, independentemente das consequências. Ele estava dizendo que se todos nós nos levantarmos, o nosso poder coletivo vai destruir as forças que se opõem a nós. Jonathan viveu por estes princípios, ele foi fiel a eles, ele morreu por eles. Esta é a coisa mais honrosa que se possa imaginar. Ele alcançou uma certa imortalidade merecida na medida em que ele realmente teve a coragem de morrer de pé, em vez de viver por um momento de joelhos. Ele ficou como um exemplo, um farol para todos nós, e eu tenho reverência por ele, mesmo que ele fosse meu irmão mais novo.

\section{Wald: O noticiário disse hoje que Tom Hayden ${ }^{2}$ declarou em frente ao Con- gresso da Associação Nacional de Estudantes que ocorrerão mais ações como a tentativa de Jonathan. Você concorda? \\ Jackson: Eu tenho pensado muito sobre a situação. Eu não estou dizendo que essas} táticas em particular, até mesmo quando executadas com sucesso, constituam a única forma revolucionária válida neste momento. Obviamente, elas não o são. Também deve haver atividades de organização de massas, incluindo grandes manifestações não violentas, a educação dos setores sociais menos desenvolvidos, e assim por diante. Estas coisas são essenciais. A revolução deve continuar em todos os níveis. Mas isso é precisamente o que faz com que essas táticas sejam necessárias, e demasiados autoproclamados revolucionários se equivocaram sobre este ponto. Tais táticas como as empregadas por Jonathan representam todo um nível - toda uma dimensão - da luta que tem permanecido quase sempre ausente do cenário estadunidense. E se é verdade que a luta armada em si e a partir de si, não basta para levar à revolução, tampouco bastam as várias outras formas de atividade. A dimensão guerrilheira do movimento, encoberta, armada, se encaixa como uma luva com a dimensão ostensiva; as duas dimensões podem e devem ser vistas como aspectos inseparáveis do mesmo fenômeno; nenhuma dimensão pode ser bem sucedida sem a outra.

Vendo as coisas objetivamente, podemos facilmente determinar que a dimensão aberta do movimento está relativamente bem desenvolvida neste momento. Ao longo dos últimos doze anos, temos visto a criação de um vasto movimento de massas em oposição ao establishment neste país. Eu não vou me aprofundar neste tema, porque eu tenho certeza de que todo mundo já sabe do que eu estou falando. Deve ser suficiente observar que nos últimos dois anos, o movimento tem repetidamente se mostrado capaz de colocar até um milhão de pessoas nas ruas em qualquer momento para expressar sua oposição à guerra imperialista na Indochina [esta parece ser uma referência ao Ato pelo Fim da Guerra no Vietnã, organizado em novembro de 1969 em Washington, DC]. A dimensão secreta do movimento está, comparativamente, muito atrasada neste momento atual. Em parte, isto se deve à própria natureza da atividade em questão: guerrilhas começam sempre com um pequeno número de pessoas. Mas, mais sobre este ponto, eu acho que a situação é resultado de ter havido uma forte resistência à ideia da luta armada por grande parte da suposta liderança, especialmente da liderança branca do movimento. Eu os ouço argumentando de forma

2 Nota da edição em inglês: Isto ocorreu no período anterior a Hayden ter abandonado a luta revolucionária. 
contrária à história, à lógica, ao simples senso comum, e tudo o mais que luta armada é desnecessária, mesmo "contraproducente". Eu os ouço discutirem da forma mais estupidamente falaciosa que se possa imaginar que a dimensão aberta do movimento pode levar à revolução por conta própria. Esta é a mais pura bobagem, e "líderes" que se envolvem em tal murmúrio devem ser descartados sem hesitação.

Podemos apresentar uma regra simples: a probabilidade de mudanças sociais significativas nos Estados Unidos podem ser medidas pelo grau em que o fator guerrilheiro da luta, secreto, armado, é desenvolvido e consolidado. Se os contrarrevolucionários e os tolos que se arvoram como líderes, enquanto resistem ao desenvolvimento da capacidade armada do movimento forem suplantados, e a luta for, portanto, capaz de avançar em uma direção adequada, acho que vamos ver uma mudança revolucionária no país, em breve. Se, por outro lado, essa liderança for bem sucedida em fazer o trabalho do Estado, ou seja, convencer a maioria das pessoas a se apartarem da luta armada, e isolar aqueles que se comprometem a atuar como guerrilheiros do apoio das massas, que justamente deve ser deles - então a revolução será atrasada. Teremos aqui uma situação muito semelhante a do Chile, aonde o establishment permite que uma certa quantidade de conquistas sociais aparentes sejam obtidas, mas está pronta para retirar essas "conquistas" sempre que for conveniente. Você pode guardar as minhas palavras sobre isso: a não ser que uma verdadeira revolução ocorra, tudo o que foi adquirido durante as lutas da última década será perdido durante os próximos dez anos. Pode até não levar tanto tempo. ${ }^{3}$

No momento atual, vejo uma série de sinais muito esperançosos - indicações muito positivas de que uma verdadeira força revolucionária está emergindo. Mais destacadamente, é claro, o caminho tomado pelo Partido dos Panteras Negras está correto. Mas há muitos outros exemplos que eu poderia citar. Mesmo na comunidade branca, temos visto o desenvolvimento, ou, pelo menos, o início do desenvolvimento, do que é necessário, com a criação da organização Weatherman. Temos claramente um longo caminho a percorrer, mas estamos caminhando, e isso é o que é importante no momento. O próprio fato de que Tom Hayden, que certamente é um revolucionário branco, esteja disposto a fazer a declaração que ele fez, e diante da audiência para a qual ele o fez, indica a verdade disto. Então, sim, eu tendo a concordar com ele e espero que estejamos ambos corretos. Pude ser claro?

\footnotetext{
Wald: Sim. Você vê uma relação entre o que aconteceu no Marin County Civic Center, entre o que Jonathan e os outros irmãos fizeram, e os tipos de coisas que acontecem no Terceiro Mundo, por exemplo, na América Latina?

Jackson: Bem, com certeza. Jonathan era um estudioso... Ele era um irmão com pensamento militar. Ele era um estudioso de Che Guevara e Ho Chi Minh, de Giap e Mao, e muitos outros. Tupamaros, Carlos Marighella. Ele prestava muita atenção aos outros guerrilheiros existentes, outras organizações revolucionárias, culturas revolucionários em todo o mundo. Ele estava muito consciente do que estava acontecendo na América do Sul e, bem, vamos apenas dizer que cerca de noventa e nove por cento da nossa conversa foi centrada em coisas militares. Eu o conhecia bem. Ele compreendeu.
}

3 Nota da edição em inglês: Na verdade, levou um pouco mais de tempo; a administração Reagan da década de 80 foi necessária para validar a previsão de Jackson. 
Wald: Eu ia perguntar se os revolucionários cubanos tiveram um significado de forma concreta para você e Jonathan.

Jackson: Hmmmm... Eu creio que não para o Jonathan. Mas para mim sim, porque eu estava na prisão. Eu estava apenas começando o meu tempo aqui quando Castro, Che e o restante encaminharam a revolução lá para um desfecho bem sucedido. E o alarme que se espalhou por todo o país, especialmente, você sabe, dentro do establishment e da polícia... Bem, vamos apenas dizer que eu, como um recém-feito prisioneiro, gostei muito disso. A libertação de outros, à custa do establishment, foi um impulso vicário no momento em que eu mais precisava. E, como resultado, eu sempre senti muito carinho pela Revolução Cubana.

Wald: Então você não era um anticomunista, quando você veio para a prisão?

Jackson: Ah, eu nunca fui um anticomunista. Eu suponho que você poderia dizer que eu não tinha muito conhecimento do comunismo, quando eu entrei, e assim eu não era pró-comunista de forma significativa. Mas eu nunca fui “anti”.

Wald: Mas inicialmente você não achou terrível que Cuba tinha "se tornado comunista"?

Jackson: Não, não, não! Isso é o que eu estou tentando lhe dizer. Eu estou tentando explicar que eu sempre fui fundamentalmente antiautoritário. $\mathrm{O}$ comunismo veio mais tarde. E quando a revolução cubana aconteceu, o simples fato dela ter perturbado tanto as autoridades daqui me fez admirá-la imediatamente e me fez querer pesquisá-la muito mais. A ideia era que, se eles não gostam disso, é porque deve ser bom. Compreende? E é isso que me levou a estudar seriamente o socialismo. Devo muito da minha própria consciência para a revolução cubana. Mas isso sou eu. Isso não significa que necessariamente foi assim com o Jonathan. Ok?

Wald: O fato de um país minúsculo e tão perto de Florida ter realizado uma revolução bem sucedida deu-lhe a sensação de que: "Se eles podem fazê-lo, nós podemos fazê-1o"?

Jackson: Sim, tanto naquela época quanto agora. Isso me levou a considerar o mito da invencibilidade. Você sabe, a ideia de invencibilidade militar dos EUA foi completamente destruído pela revolução cubana. Os EUA apoiaram Batista com mísseis e aviões, todo o necessário, e mesmo assim ele foi derrotado. Ele foi destruído por uma guerra de guerrilhas, a mesma coisa que está acontecendo no Vietnã agora. E os EUA estão perdendo novamente. O Viet Cong, eles pegam esses aparelhos sofisticados - as melhores coisas que as melhores mentes militares do mundo ocidental podem produzir - eles as pegam, as empacotam e atiram-nas de volta na cara desses idiotas imperialistas. Cuba e agora o Vietnã; esses episódios capturaram minha atenção. Tento aprender as lições de sucessos de outros povos. Agora, nesse sentido, eu tenho certeza de que a revolução cubana tinha significado para Jonathan, também.

Wald: Eu vejo que o nosso tempo está quase esgotado. Você tem alguma última observação que gostaria de fazer?

Jackson: Sim, eu gostaria de dizer PODER AO POVO! E eu gostaria de dizer que, com isso, quero dizer todo o poder, e não apenas o tipo de poder simbólico que o establishment está preparado para nos conceder em benefício de seus próprios fins. 
Eu gostaria de dizer que a única maneira de experimentarmos mudanças é tendo o verdadeiro poder necessário para fazer tornar realidade as mudanças que queremos. Eu gostaria de dizer que o establishment nunca vai ser persuadido a nos dar o poder real, ele nunca vai ser enganado, ele nunca vai se sentir culpado e mudar sua forma. A única maneira de nós obtermos o poder que precisamos para mudar as coisas é conquistando-o, através da oposição aberta, brutal, física ao establishment. Eu gostaria de dizer que temos que usar, como dizia Malcolm X, todos os meios necessários para tomar o poder. Eu gostaria de dizer que não temos alternativas reais neste temo, $\mathrm{e}$ que isso é ridículo ou pior para pensar que temos. Isso é o que eu gostaria de dizer. 